\title{
ITINERÁRIO MACHADIANO: UMA PROPOSTA DE APLICAÇÃO DO LETRAMENTO LITERÁRIO VISANDO FORMAÇÃO DO LEITOR
}

\author{
Marcela Verônica da Silva \\ Rita de Cássia Lamino de Araújo Rodrigues
}

\begin{abstract}
RESUMO
Corroborando o fato de o Letramento literário ser prática social e, como tal, constituir-se em responsabilidade da escola, este artigo visa apresentar uma proposta pedagógica que permita ao professor a aplicação de um itinerário rumo à apreensão da obra de Machado de Assis por alunos do Ensino Fundamental II. Esse itinerário corresponde às etapas de motivação, introdução, leitura, interpretação e expansão elencadas por Cosson (2006).

PALAVRAS-CHAVE: Machado de Assis; leitor; letramento literário.
\end{abstract}

Um pouco mais de atenção daria ao leitor um pouco mais de equidade. (Machado de Assis. "Notas semanais". In: O Cruzeiro, 16 de junho de 1878).

\section{Introdução}

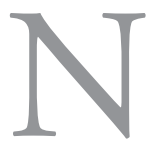

o panorama da literatura nacional, Machado de Assis é um dos escritores de maior prestígio. Sua obra, composta por enredos conflituosos caracterizados pelo uso de linguagem ambígua e irônica destaca-se por representar "os homens que sensíveis à mesquinhez humana e à sorte precária do indivíduo, aceitam por fim uma e outra como herança inalienável, e fazem delas alimento de sua reflexão cotidiana” (BOSI, 2001, p. 176). Desse modo, além de contribuir para a necessidade de fabulação do 
leitor, a literatura machadiana o leva a questionar e refletir a respeito da vida do homem em sociedade, de seus valores morais e éticos, de seus sentimentos, atitudes, virtudes e defeitos, contribuindo para o enriquecimento da percepção de si e do mundo ao seu redor. Enfim, permite que o leitor "responda melhor à sua vocação de ser humano" (TODOROV, 2012, p. 24).

Vista dessa forma, a obra de Machado de Assis confirma a função humanizadora da literatura que consiste

no processo que confirma no homem aqueles traços que reputamos essenciais, como o exercício da reflexão, a aquisição do saber, a boa disposição para com o próximo, o afinamento das emoçôes, a capacidade de penetrar nos problemas da vida, o senso da beleza, a percepção da complexidade do mundo e dos seres, o cultivo do humor. A literatura desenvolve em nós a quota de humanidade na medida em que nos torna mais compreensivos e abertos para a natureza, a sociedade, o semelhante. (CANDIDO, 2004, p. 180)

Apresenta, outrossim, linguagem elaborada, de caráter atemporal e abarca toda uma tradição literária. Contribui para a formação intelectual, o senso crítico e o enriquecimento linguístico, artístico e cultural dos leitores, na medida em que a leitura dos clássicos atribui "forma às experiências futuras, fornecendo modelos, recipientes, termos de comparação, esquemas de classificação, escalas de valores, paradigmas de beleza”. (CALVINO, 1997, p. 10)

Por esse papel na formação dos leitores, a obra de Machado de Assis é indispensável ao currículo da disciplina de Língua Portuguesa do Ensino Fundamental e do Ensino Médio. No entanto, é sabível que há por parte dos alunos - e muitas vezes também dos professores - uma resistência a essa literatura considerada difícil. Parte dessa resistência justifica-se pelo modo como a leitura literária vem sendo trabalhada no contexto escolar devido, em alguns casos, à falta do hábito de leitura dos professores e ao seu desconhecimento de metodologias que os auxiliam na prática do ensino da literatura em sala de aula. Alheios a essas metodologias e agarrados ao material didático, tendem a ler com os alunos apenas os fragmentos e a indicar atividades de interpretação de texto com respostas já preestabelecidas que não favorecem a reflexão do aluno. 
As obras machadianas presentes nos livros didáticos funcionam, outras vezes, como ensejo para o estudo da história da literatura, ou seja, moldam o olhar do aluno para a busca de elementos formais e ideológicos comuns às características de determinada escola literária.

No caso específico do Ensino Médio, a leitura das obras de Machado de Assis muitas vezes é imposta: a ameaça das avaliações, em especial, do vestibular, exige a reprodução mecânica do que foi explicado pelo professor, sob a influência da crítica literária, o que faz com que muitos jovens, ao invés de lerem os livros, procurem resumos facilmente encontrados na internet. Nesses casos, a leitura feita pelos alunos, "será uma leitura sofrida que dificilmente despertará o verdadeiro interesse pela literatura como experiência estética, capaz de ampliar o seu universo afetivo e intelectual e influenciá-lo na compreensão de si e do universo em que vive”. (ANTUNES, 2015, p. 4)

Isso ocorre porque o trabalho com o texto literário assume o que Lígia Chiappini Moraes Leite (2005, p. 96) chama de concepção "bancária" do ensino e da aprendizagem. A figura do professor é associada à transmissão do "saber" alheio, ou seja, do pensamento de críticos e dos autores dos manuais didáticos. Aos alunos não é oferecida a oportunidade de participar do "exercício mágico de interpretação do texto" (COSSON, 2006, p. 112). Eles são transformados em meros receptores daquilo que os críticos literários pensam a respeito da obra literária. Utilizada dessa forma, a literatura, e, em especial, a obra de Machado de Assis, distancia-se das práticas sociais dos estudantes e perde a sua função primordial que consiste no auxílio à formação do caráter humano.

Para que o ensino da literatura em sala de aula seja eficiente, é necessário que a prática didática leve em consideração as manifestaçóes do aluno em relação à obra literária. É verdade, conforme afirma Todorov (2012, p. 31), que o centro da obra não se resume à expressão subjetiva do aluno e que é importante que este adquira certo conhecimento a respeito da história literária e de alguns conceitos da análise estrutural do texto. No entanto, a prática dessas premissas não pode substituir o sentido da obra que é o seu fim. Para o pesquisador a análise da obra feita na escola deve deixar de privilegiar os estudos dos teóricos da literatura e da linguística em prol do "acesso ao sentido dessas obras - pois postulamos que o sentido, por sua vez, nos conduz a um conhecimento do humano, o qual importa a todos" (TODOROV, 2012, p. 89). 
Compartilhando desse mesmo pensamento, Rildo Cosson, embasado nos dizeres de Ligia Chiappini Moraes Leite, considera que o professor não deve apresentar o texto literário como um "monumento", inserido nas aulas apenas como objeto de admiração e adoração do gênero humano. Antes, cabe a ele criar condiçôes para que o encontro do aluno com a literatura seja legítimo, "pleno de sentido para o texto literário, para o próprio aluno e para a sociedade em que todos estão inseridos" (COSSON, 2006, p. 29).

Pensando nesse estreitamento nas relaçóes entre leitor e literatura machadiana, este artigo tem por objetivo sugerir uma abordagem didática pautada na sequência expandida do método do Letramento literário, criado por Rildo Cosson (2006). A aplicação desta sequência envolve um percurso ou um itinerário de leitura, que tem como mapa a novela O Menino e o Bruxo (2007) do escritor Moacyr Scliar. A escolha desta obra justifica-se por seu formato de hipertexto, já que é marcado por constantes remissivas não apenas aos contos de Machado de Assis, mas também a outros textos, como ao poema "A um bruxo com amor" de Carlos Drummond de Andrade e à célebre frase do poeta inglês William Wordsworth, "O menino é o pai do homem"; e pela bricolage, montagem feita a partir de fragmentos de contos e romances machadianos. Além do formato, a obra de Scliar fornece ao leitor uma estrutura curiosa formada por um misto de biografia e ficção, gerador de uma metaficção, na qual paratextos constituídos por nota de apresentação da editora, prefácio do autor, fotografias da cidade do Rio de Janeiro do século XIX dão ao leitor - mesmo aos mais inexperientes - um conhecimento do contexto e uma prévia da leitura. Destarte, a apresentação de Machado de Assis como garoto de quinze anos, com anseios e problemas (de pessoa comum), tira o autor de seu lugar consagrado, conferindo-lhe contornos humanos, o que facilita a identificação entre obra e leitor e permite - mesmo que de modo indireto - o contato com o universo literário machadiano.

\section{Machado de assis à luz do letramento literário}

Roland Barthes afirma que o prazer de escrever não assegura ao escritor o prazer de seu leitor. Apenas quando o leitor é absorvido pelo texto é que "Um espaço de fruição fica então criado." (BARTHES, 1987, p. 8-9). Em seu tempo, Machado de Assis conquistou muitos leitores e, - ainda em vida -, 
consagrou-se como um dos autores mais respeitáveis do Brasil. Tornou-se canônico por seu estilo inconfundível, pautado na erudição da escrita e no conteúdo marcado por uma fina ironia que deixa à mostra traços de melancolia. Sua obra requer um leitor que, segundo Iser (1996), seja capaz de "seguir as pistas do texto". Assim, para que a literatura machadiana absorva o leitor, esse leitor deve ser preparado para recebê-la. Deve ser capaz de seguir tais "pistas". Nesse sentido, a escola deve buscar meios que promovam a aproximação entre o aluno e a literatura.

O método denominado Letramento literário, proposto e desenvolvido por Rildo Cosson, apresenta-se como um meio eficaz de trabalho com a obra literária em sala de aula. Pautando-se nessa prerrogativa, apresenta-se, a seguir, uma possibilidade de aplicação desse método para as séries finais do Ensino Fundamental II.

O ponto de partida corresponde à motivação, que consiste em um momento imprescindível, pois prepara o aluno para entrar em contato com o texto. Sendo assim, na primeira aula, o professor escreve na lousa a frase do poeta inglês Wordsworth "o menino é o pai do homem", e, em seguida, questiona os alunos sobre o que a afirmativa sugere. A partir da discussão feita, pede-se para que eles escrevam em seus cadernos um pequeno texto sobre como eles são (no presente) e como se imaginam no futuro. Para tanto, o professor propóe a seguinte dinâmica: você encontrou uma máquina do tempo e ela o transporta para o futuro, cinquenta anos adiante. Nesse futuro, você se encontra consigo mesmo, adulto. Escreva um texto sobre esse encontro. Após a etapa de escrita, o professor pede para que os alunos leiam seus textos para serem comentados em sala de aula. Desse modo, é possível conduzir as discussóes trazendo à tona a frase do poeta inglês mencionada anteriormente.

$\mathrm{Na}$ aula seguinte, o professor lê em voz alta a introdução do livro $\mathrm{OMe}$ nino e o Bruxo e a apresentação de seu autor, Moacyr Scliar. Para tanto, apresenta informaçóes básicas sobre o autor, - como a admiração do escritor por Machado de Assis, atentando também para algumas características de sua escrita, principalmente as que dizem respeito aos atributos do gênero fantástico. Em seguida, apresenta o livro chamando a atenção para o seu título e para a imagem da capa, procurando levantar indícios e instigar a criaçáo de hipóteses pelos alunos em relação à história que deverá ser lida em casa. Para estimular a leitura, o professor lê as informaçóes a respeito do texto presente na contracapa: 
No Rio de Janeiro do século XIX, um garoto mulato, pobre e gago acorda de um sonho em que se vê um escritor famoso rodeado de gente importante que o olha com respeito e admiração. Mas sua realidade é muito diferente: logo ele estará nas ruas, tímido e triste, tentando vender os doces que sua madrasta prepara. Não tem sorte, não vende nada... E, no entanto, um mágico acontecimento irá mudar para sempre sua vida, produzindo um encontro que será fundamental para ele se tornar uma das maiores celebridades brasileiras. Como o menino Joaquim Maria se transformou no grande Machado de Assis é o que você verá nessa surpreendente ficção de Moacyr Scliar, baseada em fatos reais (SCLIAR, 2006, s/p).

É importante que o professor comente a respeito do motivo que o faz selecionar esse livro, justificando que a escolha se dá pelo fato de apresentar a vida e a obra de Machado de Assis, um dos escritores mais importantes de Literatura Brasileira. Deve ser ressaltado que, no livro, Scliar preenche as lacunas da vida enigmática de Machado de Assis por meio da imaginação e transcreve trechos de alguns dos seus principais textos de uma forma inusitada. Tendo em vista que a função da introdução é despertar o interesse do aluno pela obra, o professor deve ter em mente que o tempo dedicado a essa etapa do método não deve se estender mais do que uma aula.

Estabelecido o prazo para a leitura de O Menino e o Bruxo, o professor, de modo a acompanhar e verificar a leitura propóe os intervalos de leitura, que, de acordo com Cosson, "podem ser feitos por meio de uma simples conversa com a turma sobre o andamento da história ou atividades mais específicas" (2006, p. 62). Esses intervalos são "momentos de enriquecimento da leitura do texto principal” (COSSON, 2006, p. 81). Levando em consideração que a obra de Scliar dialoga com a de Machado de Assis fazendo analogias aos seus principais textos por meio da inserção de personagens e colagem de fragmentos de textos machadianos em seu enredo, propóe-se, para a realização dos intervalos, o acompanhamento de leitura de dois contos machadianos: "Pai contra Mãe" e "A Missa do Galo", mencionados em O Menino e o Bruxo; e de trechos do romance $D$. Casmurro, principalmente os que apontam para a relação conflituosa de Bentinho e Capitu - personagem também trazida para a obra de Scliar. 
Para o primeiro intervalo, propóe-se que o professor combine com os alunos a leitura do livro até o momento em que há o encontro entre José Maria e Machado de Assis. Nesse momento, o menino descobre que o homem que o socorreu é um escritor. O menino revela a Machado de Assis seu interesse em escrever uma história com o tema da escravidão. Após a realização da leitura, o professor pode questionar os alunos acerca de suas impressóes, sentimentos, suas possíveis dificuldades e perguntar se houve a curiosidade em conhecer o restante da história mencionada pelo jovem Joaquim Maria a respeito da escravidão.

A história mencionada alude ao conto "Pai contra Mãe". Publicado em 1906, em Relíquias da Casa Velha, o conto apresenta a história de Cândido, um homem que tem por profissão a caça de escravos. Diante da miséria e impossibilidade de sustentar seu filho recém-nascido, o personagem vê como única solução a captura de uma escrava fugitiva, que, estando grávida, lhe implora a liberdade, porém é entregue a seu senhor acabando por sofrer um aborto. Antes de iniciar a leitura do conto, propóe-se que o professor chame a atenção dos alunos para o seu título, pedindo para que eles anotem em seus cadernos o que este sugere a respeito da temática que será desenvolvida no conto, se é possível perceber de que personagem irá tratar e a época em que a história ocorre. Essas perguntas instigam a expectativa diante do texto e incentivam as dúvidas que serão sanadas com a leitura.

Dando sequência à atividade, o professor distribui entre os alunos cópias do conto machadiano para a realização da leitura silenciosa, seguida de atividade de interpretação para um maior conhecimento da estrutura do texto. A atividade deve ser desenvolvida em dupla, assim como, o desenvolvimento de uma reflexão crítica a respeito de sua temática. Para isso, pede para que os alunos identifiquem os personagens, o foco narrativo, trechos em que o narrador conversa com o leitor e dá sua opiniáo sobre os acontecimentos e utiliza o tom irônico; a temática, o conflito da narrativa e o momento de maior tensão. Em seguida, os alunos são convidados a exporem suas respostas de modo a levantar uma discussão a respeito do conto. Neste momento, o professor aproveita para retomar as hipóteses elaboradas pelos alunos a respeito do título para verificar se o texto satisfez suas expectativas. Incentiva a turma a expressar suas emoções em relação ao texto, refletindo a respeito da condição do escravo e, principalmente, do trabalhador branco livre e pobre na sociedade brasileira 
escravista, no final do século XIX, que tinha uma condição de miséria, perdendo sua autonomia e vivendo quase que de modo semelhante aos escravos.

Por fim, o professor pede para que os alunos expliquem o motivo da alusão desse conto em $O$ Menino e o Bruxo e sua relação com o escritor Machado de Assis. Nesse momento, é importante que o professor leve a classe a perceber que, vivendo em uma sociedade escravocrata, sendo descendente de escravos, Machado de Assis conseguiu mostrar as contradiçóes vivas desse meio apresentando o homem "malvado e perverso, ou humilde e humilhado, ora como joguete do destino, ora como quem exercita o livre-arbítrio, rico, pobre, opressor e vítima, mas homem incapaz de encontrar sentido para a vida" (FACIOLI, 2002, p. 32).

O segundo intervalo focaliza o modo ambíguo como Machado de Assis constrói grande parte dos seus enredos, por meio da construção de textos que primam pela sugestão e são repletos de dúvidas e negatividade. Para tanto, utiliza a deixa oferecida pelo livro O Menino e o Bruxo, na qual Machado de Assis incentiva Joaquim Maria a escrever um conto envolvendo uma jovem senhora e um adolescente de dezessete anos, na noite do Natal. O professor pede para que os alunos leiam, em casa, até o capítulo cinco. No dia marcado, pergunta aos alunos se eles lembram-se da referência feita ao conto em $O$ Menino e o Bruxo. Caso a resposta seja afirmativa, pede para que eles comentem a maneira como o conto machadiano é mencionado no texto. Em seguida, inicia a leitura do conto "Missa do Galo".

Pertencente à coletânea de contos Papeis Avulsos (1899), a narrativa em primeira pessoa apresenta o encontro casual, na véspera de Natal, entre Nogueira, adolescente de 17 anos, que estava na casa do escrivão Menezes, para terminar os estudos preparatórios, com Conceição, jovem senhora de trinta anos, esposa de Menezes, que aceita resignadamente o relacionamento extraconjugal do marido. Passados alguns anos, Nogueira revive esse encontro, ocorrido momentos antes da Missa do Galo, quando, estando na sala lendo à espera do amigo com quem iria ao evento religioso é interceptado por Conceição. Os dois conversam intimamente sobre vários assuntos, até que o amigo o chama. No dia seguinte, Conceição se comporta como nada tivesse acontecido na véspera. A descrição feita de Conceição deixa entrever a figura de uma mulher ambígua, proporcionando uma atmosfera de dúvidas e incertezas, uma vez que o narrador sugere a existência da atração e sedução, porém não 
revela o que realmente aconteceu entre a jovem senhora e o garoto. De acordo com Crestani (2006, p. 4), esse contexto criado pelo narrador possibilita a formulação de duas suposições a respeito de Conceição: a primeira, de que ela tenta seduzir o jovem e trair o marido; e a segunda, de que ela, estando sozinha em casa, em plena véspera de Natal, deseja apenas ter alguém para conversar.

Diante dessas possibilidades proporcionadas pelo conto machadiano, o professor divide a sala em quatro grupos: duas equipes podem ficar responsáveis por ler o conto novamente e selecionar fragmentos que sugerem o caráter honesto de Conceição, ou seja, que não havia a intenção por parte dessa mulher em trair o marido; enquanto que as outras duas equipes ficam responsáveis por selecionar no texto os elementos que comprovariam a malícia da mulher e a tentativa de seduzir o garoto. Feito isso, a classe será convidada a realizar um debate em que cada grupo apresentará seus argumentos. Apesar das tentativas de definição do caráter e atitudes de Conceição, o professor deve frisar a ambivalência das personagens femininas machadianas, demonstrando que com uma construção não nítida a humanizaçáo da personagem torna-se ainda maior.

Dando sequência, o professor pode chamar a atenção dos alunos para o foco narrativo, questionando-os a respeito da ambiguidade gerada pelo conto, uma vez que a suspeita que recai sobre Conceição é proporcionada pelo modo como Nogueira, narrador em primeira pessoa, apresenta a personagem e a situação. Deve-se levar a classe a perceber que o fato da história ser narrada por um narrador-personagem torna seu discurso pouco confiável, pois o que nos é relatado diz respeito apenas as suas impressóes. Crestani (2006) chama a atenção para a importância de se levar em conta o narrador desse conto:

Machado de Assis, através da acertada escolha do foco narrativo, conduz a narrativa de maneira ambígua, deixando o leitor em cima do muro ou propenso a tirar conclusóes precisas. A exemplo de Dom Casmurro, nada pode ser firmado nem negado categoricamente. A respeito de toda a polêmica que gira em torno dela [Conceiçáa] esquece-se que, de fato, ela não é personagem problema da história, assim como não o é Capitu, na verdade ambas não têm vida própria dentro da narrativa, elas nem sequer podem ser consideradas como personagens, 
pois verdadeiramente, elas constituem recortes memorialistas criados ou resgatados da memória do narrador. [...] Conceição é apenas um recorte, um fragmento de um retrato de mulher criado ou resgatado da memória do narrador. [...] Toda a ambiguidade que gira em torno dela depende da maneira como o narrador, Nogueira, a vê. (CRESTANI, 2006, p. 4)

Levando em consideração a afirmação apresentada pelo estudioso, o professor incentiva a turma a vasculhar o texto em busca de indícios que comprovem as hesitaçóes e contradições desse narrador, elementos que demonstrem que o seu discurso deve ser observado com certa relevância, uma vez que o narrador tenta construí-lo de modo a manipular o leitor e levá-lo a compactuar e acreditar na sua inocência diante da experiente e sedutora: "Mais do que um narrador ingênuo, Nogueira é um narrador que se quer fazer ingênuo, procurando desviar a atenção e os juízos críticos para o comportamento de Conceição, afastando-o de si” (CRESTANI, 2006, p. 1). Com esse segundo intervalo, o aluno será capaz de refletir a respeito da escrita de Machado de Assis que prima sempre pela ambiguidade e sugestão, construindo textos inteligentes que demandam do leitor uma leitura atenta das entrelinhas, de modo a vislumbrar a possibilidade de outro sentido para o texto. Como sugere Machado de Assis ao jovem Joaquim Maria, em O Menino e o Bruxo, "A história é importante. História é o que está nas linhas; mas o que está nas entrelinhas, aquilo que não é dito, que é só sugerido, pode ser mais importante ainda” (SCLIAR, 2007, p. 50).

Para o terceiro e último intervalo, o professor combina com a turma a leitura do capítulo seis ao oito. No dia marcado, questiona os alunos a respeito do conteúdo lido, em especial no capítulo seis, que apresenta o encontro do menino José Maria com a menina Capitu. Esta usa do seu poder de persuasão e sedução para fazer com que o jovem Joaquim Maria convença o grande Machado de Assis a mudar o final da história, Dom Casmurro, que escreveu baseada em sua personalidade, mas que tem por personagem narrador um homem, Bentinho, que, passados anos, relata sua história de amor por Capitu, sugerindo uma suposta traição da jovem com seu melhor amigo Escobar, de modo a exorcizar a culpa pelo fim trágico de seu casamento. Assim, como no conto "Missa do Galo", a personalidade de Capitu é descrita ambiguamente, o que dificulta a confirmação do adultério. 
Tendo em vista que o livro O Menino e o Bruxo focaliza a personalidade forte de Capitolina, o professor aproveita para levar para a sala de aula o romance D. Casmurro. Após apresentar algumas consideraçóes a respeito do enredo para complementar o que foi descrito pelo texto de Scliar, o professor sugere a leitura do capítulo trinta e dois, "Olhos de Ressaca", em que Bento Santiago, após ouvir de José Dias que Capitu tinha os olhos de cigana oblíqua, ou seja, espelho de sua astúcia, malícia e fingimento, busca comprovar por si próprio a descrição feita por José Dias, acabando por ser arrastado, seduzido por aquele olhar atraente e traiçoeiro de Capitu, referido por "olhos de ressaca”. Nesse momento, o professor pede para que os alunos tentem explicar o título do capítulo. Feito isso, inicia-se a leitura. Ao final, os alunos são convidados a pensar a respeito da personagem Capitu e sua densidade psicológica. Terminada esta parte, o professor questiona os alunos a respeito do narrador, tentando evidenciar semelhanças entre o narrador desse romance e do conto "Missa do Galo". O objetivo é levar o aluno a entender que o foco narrativo em primeira pessoa demanda a necessidade de o leitor ficar atento, uma vez que os personagens masculinos apresentam apenas suas próprias visóes dos fatos.

Em seguida, o professor faz uma enquete com a turma para saber se os alunos, tendo em vista o que leram a respeito de Capitu no capítulo "Olhos de ressaca" de $D$. Casmurro, atenderiam ao pedido de Capitu - feito ao menino Joaquim Maria - em O Menino e o Bruxo. No livro de Scliar, a menina Capitolina deseja que Machado de Assis reescreva sua história, apresentando "uma jovem que deseja viver um grande caso de amor, de paixão, que transforme sua vida" (SCLIAR, 2007, p. 68). Deseja ter sua imagem modificada, para que os leitores deixassem de concebê-la como adúltera ou dissimulada. Machado de Assis, porém, justifica a caracterização da personagem e faz Joaquim Maria pensar acerca de sua posição de escritor, uma vez que o clichê do final feliz levaria a obra machadiana à banalidade.

Terminados os intervalos de leitura e consequentemente a leitura de toda a obra, chega o momento da primeira interpretação que, de acordo com Cosson, "destina-se a impressão geral da obra" (COSSON, 2006, p. 83). Essa é a ocasião em que os alunos são convidados a exteriorizar e registrar suas reflexôes e sentimentos decorrentes da(s) leitura(s). Para tanto, primeiramente o professor promoverá uma discussão com todos os alunos, retomando suas 
hipóteses iniciais sobre o título do livro O Menino e o Bruxo para saber se a história narrada correspondeu às suas expectativas. Em seguida, pedirá a eles que se organizem em duplas, incubindo a cada aluno a responsabilidade de questionar o colega sobre o que mais o surpreendeu na obra de Scliar e nos textos de Machado de Assis abordados em sala de aula e quais emoçóes foram despertadas pela leitura. Os alunos levantarão argumentos para justificar suas respostas (que podem ser filmadas, caso todos concordem). Caso proceda à filmagem, na aula seguinte os alunos poderão assistir aos seus depoimentos.

Terminada essa primeira interpretação, inicia-se o momento da contextualização que consiste no "aprofundamento da leitura por meio dos contextos que a obra traz consigo" (COSSON, 2006, p. 86). Junto a ela, será trabalhada a segunda interpretação. Para a realização dessas duas etapas do método do Letramento literário, o professor propóe à turma a criação de um documentário sobre a vida e a obra de Machado de Assis, a partir das informaçóes colhidas na leitura do livro O Menino e o Bruxo de Moacyr Scliar, tentando pensar o motivo pelo qual Scliar sugere que "o menino é o pai do homem". Para incentivá-los ainda mais, o professor pode propor a apresentação dos documentários às demais turmas da escola.

Visando enriquecer o trabalho dos alunos, o professor pode apresentar o documentário "Mestres da Literatura - Machado de Assis - um mestre na periferia do capitalismo", produzido pela Tevê Escola em parceria com a PUC e Televísion América Latina . Após assistir ao documentário, o professor pode questionar os alunos a respeito do modo como foi produzido e sobre os pontos privilegiados pelo diretor, tentando levá-los a perceber que o documentário contempla a realidade, dando-a um tônus de documento.

Feito isso, discute-se a estratégia para a realização do trabalho e organiza-se a sala em grupos, dando a cada equipe a tarefa de contextualizar uma parte da vida e da obra de Machado de Assis de acordo com o livro de Moacyr Scliar, a fim de que cada grupo produza uma parte do documentário, orientando-os a fazer um roteiro de tarefas, pesquisas em livros didáticos e sites da internet, a selecionarem imagens e organizarem textos para serem narrados e imagens para serem apresentadas em power point. Essa atividade de pesquisas e preparaçáo para apresentação visa incentivar os alunos a usarem a criatividade.

Assim, ao primeiro grupo é incumbida a tarefa de fazer a contextualização histórica do período em que Machado de Assis viveu na cidade do Rio 
de Janeiro. Para tanto, o professor orientará os alunos a pesquisarem no livro o Menino e o Bruxo, o nome de ruas e locais que Machado de Assis viveu/ frequentou. A partir dessa pesquisa, a equipe ficará responsável por contextualizar a cidade do Rio de Janeiro, no final do século XIX e início do XX, procurando informaçôes e fotografias na internet. Ainda em relação à contextualização histórica, o segundo grupo ficará responsável por pesquisar dados a respeito da vida de Machado de Assis, seus familiares, amigos, os locais onde trabalhou e conviveu até sua morte.

Ao terceiro grupo será encarregada a tarefa da contextualização estilística, ou seja, os alunos ficarão responsáveis por pesquisar, no próprio livro didático e na internet, o estilo da época e o período literário em que Machado de Assis escreveu. Os alunos deverão observar as tendências literárias em vigor na época, no caso o Realismo e Naturalismo, e de que maneira Machado de Assis, mesmo fazendo parte desse período, se afastava do modo como a maioria dos autores produziam seus textos.

O quarto grupo, terá como tarefa a apresentação da obra de Machado de Assis; para tanto, buscará no livro de Moacyr Scliar as obras citadas e fará a exposição dessas obras/contos, apresentando seus enredos, procurando observar de que maneiras foram estruturadas e organizadas pelo autor. Buscando trabalhar em conjunto com esse grupo, uma quinta equipe será formada e ficará responsável por apresentar temáticas recorrentes na ficção machadiana e suas repercussóes dentro da obra.

O sexto grupo ficará responsável pela contextualização crítica da obra de Machado de Assis. Cosson acredita que "a contextualização crítica é a análise de outras leituras que tem por objetivo contribuir para a ampliação do horizonte de leitura da turma” (COSSON, 2007, p. 88). Neste sentido, para a realização dessa tarefa, o professor orientará a equipe a procurar nos livros didáticos, roteiros de leituras, sites especializados da internet e documentários, a opiniáo dos críticos e estudiosos da literatura a respeito da obra de Machado de Machado de Assis.

O sétimo grupo será orientado a realizar a contextualização presentificadora caracterizada por Cosson (2007, p. 89) como o momento em que o professor chama a atençáo do aluno para a temática da obra e sua relação com o presente da leitura. Para a realização dessa contextualização, os estudantes são convidados a encontrar na sociedade em que vivem elementos relacionados 
às obras de Machado de Assis. Por exemplo, os alunos poderão trazer à tona os problemas sociais no contexto do Rio de Janeiro do século XIX - como a apresentada no conto "Pai contra Mãe", cujo tema da pobreza repercute de modo direto nas atitudes do personagem Cândido Neves -, e nos dias atuais; ou então, os alunos poderão ser instigados a pensar a respeito da posição da mulher no final do século XIX e no século XXI, temática do conto "A Missa do Galo" e do romance D. Casmurro. Feito isso, serão orientados a escolher alguns depoimentos para o documentário.

No dia combinado, cada equipe leva para a sala de aula a sua parte do documentário. A turma assiste ao material e inicia a tarefa de edição, ou seja, de juntar as partes e adequá-las. Também, neste momento, deve-se pensar em um título para o filme. O professor pode, ainda, nomear um grupo para ficar responsável pela tarefa da edição do documentário em casa. Concluída a edição, o professor e a turma podem convidar os demais alunos da escola para assistirem ao documentário a respeito de Machado de Assis.

Encerrada essa parte, para a atividade de expansão, o professor convida a turma para assistir ao filme Memórias Póstumas de Brás Cubas (2001), baseada no livro de mesmo nome de Machado de Assis, também referenciado na obra de Moacyr Scliar, incentivando os alunos a buscarem no filme momentos que dialogam com a obra O Menino e o Bruxo, mostrando a riqueza da obra machadiana que tanto pode ser reelaborada no livro de Scliar quanto na obra cinematográfica de André Klotzel.

\section{Considerações finais}

A intenção deste artigo foi apresentar uma proposta didática voltada para a leitura de textos literários de teor mais exigente. Como Machado de Assis é um dos escritores canônicos mais temidos pelos estudantes, dada a linguagem arcaica, tom filosófico e humor pautado na ironia, marcas emblemáticas do autor, optou-se pela escolha de um repertório de textos machadianos arrolado na obra O Menino e o Bruxo de Moacyr Scliar. A obra de Scliar transforma-se em um verdadeiro itinerário de leitura. Além de aproximar o leitor do universo da literatura de Machado de Assis pela empatia - uma vez que adota como personagem central o adolescente Joaquim Maria - ,a novela de Scliar coloca os estudantes em contato direto com a escrita machadiana, uma vez que uti- 
liza a técnica da bricolage, construindo um painel de fragmentos de contos e romances de Machado de Assis, instigando, assim, a curiosidade do leitor que deseja conhecer mais profundamente tais textos. Outrossim, apresenta paratextos que permitem ao aluno conhecer o contexto no qual se deu a criação literária machadiana e as razóes de Scliar ao se valer de tais informações para criar uma obra sobre o Machado de Assis.

A proposta didática pautou-se nos passos do método do Letramento literário descritos por Rildo Cosson que, além de descrever, também sugeriu atividades em oficinas, cujo objetivo era a de incentivar os jovens à leitura atenta e a analisar/interpretar as obras canônicas. Seguindo este modelo, a proposta apresentada segue o mesmo intuito: preparar os jovens leitores para a leitura e interpretação das obras canônicas. No entanto, as atividades descritas neste artigo devem ser entendidas como sugestão de prática pedagógica, que pode ser utilizada na íntegra ou ser adaptada, de acordo com a realidade do professor e com as necessidades dos alunos.

\section{Referências}

ANTUNES. Benedito. O Ensino da Literatura Hoje. Fronteiraz: Revista Digital do Programa de Estudos Pós-Graduados em Literatura e Crítica Literária. PUC-SP, no 14: 3-17, São Paulo, jul. 2015, http://revistas.pucsp.br/ fronteiraz. 15/08/2015.

ARAÚJO, Rita de Cássia Lamino de; SILVA, Marcela Verônica. A Estética da Recepção e sua aplicabilidade pelo Método Recepcional: uma apresentação de Machado de Assis. Fronteiraz: Revista Digital do Programa de Estudos Pós-Graduados em Literatura e Crítica Literária. PUC-SP, no 14: 18-19, São Paulo, jul. 2015, http://revistas.pucsp.br/fronteiraz, 15/08/2015.

ASSIS, Machado de. Obra Completa. Rio de Janeiro: Nova Aguilar, 1994.

ASSIS, Machado de. O Cruzeiro. In: . Obras completas. Vol. 23. Rio de Janeiro: W. M. Jackson Inc, 1950.

BARTHES, Roland. O prazer do texto. Trad. J. Guinsburg. 4 ed. São Paulo: Perspectiva, 1996.

BOBERG, Hiudéa Tempesta Rodrigues; STOPA, Rafaela. Leitura Literária na sala de aula: propostas de aplicação. Curitiba: CRV, 2012. 
CALVINO, Ítalo. Por que ler os clássicos. Trad. Nilson Molin. São Paulo: Companhia das Letras, 1997.

CANDIDO, Antonio. Literatura e Formação do Homem. In: Textos de Intervenção. São Paulo: Duas Cidades, 2002.

. O Direito à literatura. In: Vários Escritos. 3 ed. Rev. e ampl. São Paulo: Duas Cidades, 1995.

CRESTANI, Jaison Luís. O narrador sob suspeita: uma leitura do conto "Missa do Galo" de Machado de Assis. Anais do X Congresso Internacional da ABRALIC. Rio de Janeiro, 2006, http://www.idelberavelar.com/abralic/ txt_14.pdf., 15/08/ 2015.

COSSON, Rildo. Letramento literário: teoria e prática. São Paulo: Contexto, 2006.

FACIOLI, Valentin. Um Defunto Estrambólico: análise e interpretação das Memórias póstumas de Brás Cubas. São Paulo: Nankin, 2002.

ISER, Wolfgang. $O$ ato da leitura: uma teoria do efeito estético. 2 v. São Paulo: Ed. 34, 1996-1999.

KLOTZEL, André. Memórias Póstumas. [Filme - vídeo]. Produção e Direção de André Klotzel. Brasil: Videolar - Indústria Brasileira, 2001, VHS, 110 min, color. Son. Port..

LEITE, Lígia Chiappini Moraes. Invasão da catedral: literatura e ensino em debate. Porto Alegre: Mercado Aberto, 1983.

PAULINO, Graça; COSSON, Rildo. Letramento literário: para viver a literatura dentro e fora da escola. In: RÖSING, Tânia M. K.; ZILBERNAM, Regina (Orgs.). Escola e leitura: velha crise, novas alternativas. São Paulo: Global, 2009.

SCLIAR, Moacyr. O Menino e o Bruxo. São Paulo: Ática, 2007.

SILVA, Antônio Augusto. Mestres da literatura: Machado de Assis - um mestre na periferia do capitalismo (Filme - documentário). Direção de Antônio Augusto Silva. Brasil: TV Escola / Polo de Imagem / TV PUC / Televisión América Latina,2007, 25 min, color. Son. Port, http://tvescola.mec.gov.br/tve/video/ mestres-da-literatura-machado-de-assis-um-mestre-na-periferia, 30/09/ 2015.

TODOROV, Tzvetan. A Literatura em Perigo. Trad. Caio Meira. Rio de Janeiro: DIFEL, 2009.

WORDSWORTH, William. Poesia selecionada. Trad. Paulo Vizioli. São Paulo: Mandacaru, 1988. 


\title{
ITINERARY MACHADO DE ASSIS: A READER TRAINING A PROPOSAL FOR LITERARY LITERACY APPLICATION
}

\begin{abstract}
Corroborating the fact that the literary literacy is a social practice and as such constitute in school responsibility, this article aims to present a pedagogical proposal that allows the teacher to apply a pilgrimage to the seizure of Machado de Assis's work by students the Elementary School. This route corresponds to the stages of motivation, introduction, reading, interpretation and expansion listed by Cosson (2006).

PALAVRAS-CHAVE: Machado de Assis; reader; literary literacy
\end{abstract}

Recebido em: 30/10/2015 Aprovado em: 25/01/2016 